\title{
COMPETITIVE INHIBITION OF PHYTIC ACID ON ENZYMATIC BROWNING OF CHESTNUT (CASTANEA MOLLISSIMA BLUME)
}

\author{
G.P. LI ${ }^{\mathrm{a}}$, D. ZHOU ${ }^{\mathrm{a}}$, L.N. KAN ${ }^{\mathrm{a}}$, Y.W. WU $\mathrm{U}^{\mathrm{b}}$, J.F. FAN ${ }^{\mathrm{a}}$ and J. OUYANG ${ }^{\mathrm{a} *}$

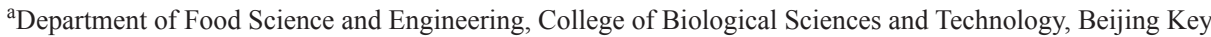 \\ Laboratory of Forest Food Process and Safety, Beijing Forestry University, No.35, Qinghuadonglu, Haidian \\ District, 100083 Beijing. China \\ ${ }^{b}$ Beijing Center for Physical and Chemical Analysis, Beijing Food Safety Analysis and Testing Engineering \\ Research Center, No. 27, Xisanhuan Beilu, Haidian District, 100089 Beijing. China
}

(Received: 27 July 2016; accepted: 15 August 2016)

\begin{abstract}
The inhibitory effects of phytic acid (PA) on the browning of fresh-cut chestnuts and the associated mechanisms of PA on polyphenol oxidase (PPO) and peroxidase (POD) activities were investigated. The enzymatic browning of chestnut surfaces and interiors was suppressed by soaking shelled and sliced chestnuts in a PA solution. The specific activities of PPO and POD extracted from chestnuts declined due to inhibition by PA. PA was determined to be a competitive inhibitor of both PPO and POD by Lineweaver-Burk plots. The binding modes of PA with PPO and POD were analysed by AutoDock 4.2.
\end{abstract}

Keywords: phytic acid, chestnut, enzymatic browning, polyphenol oxidase, peroxidase

Chestnut has been a valuable food resource for centuries for the people living in East Asia, South Europe, and North Africa (Gounga et al., 2008). Chinese chestnut (Castanea mollissima Blume) is popular in East and Southeast Asia because of its delicious, sweet taste. Research on the chemical composition of chestnuts reveals the presence of various nutrients that are important for human health (De Vasconcelos et al., 2010; Blaiotta et al., 2012). In the processing of chestnut fruit, it will darken after peeling, mechanical damage, segmentation, grinding, and prolonged exposure due to enzymatic browning. The browning reaction decreases both the acceptability and nutritional quality of chestnuts (DE LA RosA et al., 2011). Enzymatic browning involves the activities of polyphenol oxidase (PPO) and peroxidase (POD), which oxidize phenols found in fruit and vegetables to anthraquinones, which then become melanins by non-enzymatic polymerization. Controlling the activity of PPO and POD is a potential strategy for the inhibition of enzymatic browning (ZHOU et al., 2015). Effective inhibitors are necessary, because traditional methods, such as heating and adjusting $\mathrm{pH}$ value, are impractical in chestnut fruit pretreatment.

Phytic acid (PA) is an antioxidant, chelating agent, and non-toxic food additive that has been used to inhibit enzymatic browning of apple juice and asparagus lettuce (CHEN et al., 2010; Du et al., 2012). The present study investigated the effects of PA on the enzymatic browning by inhibiting PPO and POD activities in fresh-cut Chinese chestnuts. Additionally, the inhibition modes and binding sites between PA and PPO and POD were determined.

\footnotetext{
* To whom correspondence should be addressed.

Phone:+86 10 62336700; fax: +86 10 62338221; e-mail: ouyangjie@bjfu.edu.cn
} 


\section{Materials and methods}

\subsection{Materials}

Chinese chestnuts were purchased from a commercial market in Beijing. The fruit were stored at $0-2{ }^{\circ} \mathrm{C}$ before use. For the PA experiment, chestnuts were divided into two groups: one group was hulled and cut into $0.5 \mathrm{~mm}$ thick slices, the other group received no treatment after hulling. The hulled chestnuts and sliced chestnuts were further divided into six groups and immersed in $0,0.01,0.02,0.03,0.04$, and $0.05 \%(\mathrm{v} / \mathrm{v}) \mathrm{PA}$ at $20^{\circ} \mathrm{C}$ for $1 \mathrm{~h}$. Then, all treated samples were stored at $4{ }^{\circ} \mathrm{C}$ for six days for measurement. All chemicals were of analytical grade and purchased from Beijing Chemicals Corporation (Beijing, China).

\subsection{Evaluation of browning degree $(B D)$}

The chestnut BD was assayed using a HP-2132 Portable Colorimeter (HANPU Optoelectronics Technology Co., Ltd. Shanghai, China) each day of storage. The total chromatism $(\Delta \mathrm{E})$ represented $\mathrm{BD}$. The $\mathrm{BD}$ of the chestnut interior (BDI) was assayed by measuring $\triangle \mathrm{E}$ in the centre of the prepared slices, while the BD of the chestnut surface (BDS) was assayed by measuring the $\Delta \mathrm{E}$ of the hulled chestnut surface. BDI and BDS of the chestnuts immediately removed from the corresponding reagents were used as a control.

\subsection{Assay of PPO and POD activities}

Chinese chestnuts $(20 \mathrm{~g})$ were homogenized in $0.05 \mathrm{M}$ citrate phosphate buffer ( $\mathrm{pH} 5.6,100$ $\mathrm{ml}$ ). The slurry was centrifuged at $0{ }^{\circ} \mathrm{C}$ and $10000 \mathrm{~g}$ for $30 \mathrm{~min}$, and the supernatant was supplemented with $0.05 \mathrm{M}$ citrate phosphate buffer (pH 5.6) to $100 \mathrm{ml}$. The protein content of the crude enzyme extract was analysed by Coomassie Brilliant Blue and determined to be $1.02 \pm 0.01 \mathrm{mg} \mathrm{ml} \mathrm{m}^{-1}$. The activities of PPO and POD were measured with a UV 2550 spectrophotometer (Shimadzu, Japan) using catechol, guaiacol, and $\mathrm{H}_{2} \mathrm{O}_{2}$ as substrates. The PPO assay mixture consisted of $0.1 \mathrm{M}$ citrate phosphate buffer $(\mathrm{pH} 5.6,3 \mathrm{ml}), 0.1 \mathrm{M}$ catechol $(1 \mathrm{ml})$, and the enzyme extract solution $(0.5 \mathrm{ml})$. The change in absorbance at $420 \mathrm{~nm}$ was measured every $30 \mathrm{~s}$ for $3 \mathrm{~min}$. POD activity was determined using a reaction system similar to that of PPO, except that the substrates were $0.05 \mathrm{M}$ guaiacol $(1 \mathrm{ml})$ and $2 \%(\mathrm{v} / \mathrm{v}) \mathrm{H}_{2} \mathrm{O}_{2}(2$ $\mathrm{ml}), 0.2 \mathrm{ml}$ of the enzyme extract was used, and the absorbance was measured at $470 \mathrm{~nm}$. PPO and POD activities are presented as specific activities and are defined as an increase in absorbance per minute in $1 \mathrm{mg}$ enzyme of reaction mixture $\left(\Delta A_{420} / \mathrm{min} / \mathrm{mg}\right.$ for PPO and $\Delta A_{470} / \mathrm{min} / \mathrm{mg}$ for POD).

\subsection{In vitro experiments of $P P O$ and POD activities in the presence of PA}

The assay methods were similar to the procedures described above, except that the crude enzyme extract solutions were mixed with different concentrations of PA. The inhibitorenzyme solutions were then added to the substrate-buffer solution. The PPO activity assay employed an inhibitor-enzyme solution containing the enzyme extract $(1 \mathrm{ml})$ and PA at the following concentrations $(1 \mathrm{ml})$ : $0,0.01,0.02,0.03,0.04$, and $0.05 \%(\mathrm{v} / \mathrm{v})$. The control sample consisted of $0.1 \mathrm{M}$ citrate phosphate buffer $(\mathrm{pH} 5.6,1 \mathrm{ml})$ and distilled water $(1 \mathrm{ml})$. The POD activity assay employed an inhibitor-enzyme solution containing the enzyme extract $(0.2 \mathrm{ml})$ and PA at the following concentrations (1 ml): 0, 0.01, 0.02, 0.03, 0.04, and $0.05 \%(\mathrm{v} / \mathrm{v})$. The control sample consisted of $0.1 \mathrm{M}$ citrate phosphate buffer (pH 5.6, $0.2 \mathrm{ml})$ and distilled water $(1 \mathrm{ml})$. 


\subsection{Kinetic study of $P A$ on $P P O$ and $P O D$}

For kinetic studies, the crude enzyme extract needed to be further purified. The crude enzyme solution mentioned above was concentrated by ultrafiltration using a Millipore Amicon ${ }^{\circledR}$ ultra- 15 concentrator with a molecular weight cut off of $30 \mathrm{kDa}$. The concentrated enzyme extract was loaded onto a Sephadex G-200 chromatography column $(10 \mathrm{~mm} \times 1000 \mathrm{~mm})$ that was pre-equilibrated with phosphate buffered saline (PBS). The sample was eluted with PBS at a flow rate of $0.33 \mathrm{ml} \mathrm{min}{ }^{-1}\left(0.063 \mathrm{BV} \mathrm{h}^{-1}\right)$, and fraction peaks of PPO and POD were obtained separately. The inhibition modes of PA on PPO and POD were determined by in vitro experiments that measured the effect of different concentrations of PA on PPO and POD activity. The PPO kinetic study consisted of sample solutions containing catechol solution (1 $\mathrm{ml}$ ) at different concentrations $(0.1,0.3,1,2,3$, and $6 \mathrm{mM}), 0.1 \mathrm{M}$ citrate phosphate buffer $(\mathrm{pH} 5.6,2 \mathrm{ml})$ with different concentrations of PA $(0,0.02$, and $0.05 \% \mathrm{v} / \mathrm{v})$, and the PPO solution $(0.2 \mathrm{ml})$ diluted with $0.05 \mathrm{M}$ PBS (pH 7.0) to approximately $300 \mathrm{U} \mathrm{PPO} / \mathrm{ml}$. The POD kinetic experiment consisted of a sample solution containing guaiacol solution $(1 \mathrm{ml})$ at different concentrations $(1,2,3,4$, and $6 \mathrm{mM}), 0.1 \mathrm{M}$ citrate phosphate buffer ( $\mathrm{pH} 5.6,2 \mathrm{ml})$ with different concentrations of PA $(0,0.01$, and $0.1 \% \mathrm{v} / \mathrm{v}), 1 \%(\mathrm{v} / \mathrm{v}) \mathrm{H}_{2} \mathrm{O}_{2}(0.2 \mathrm{ml})$, and the POD solution $(0.05 \mathrm{ml})$ diluted with $0.05 \mathrm{M} \mathrm{PBS}(\mathrm{pH} 7.0)$ to approximately $1 \mathrm{U} \mathrm{POD} / \mathrm{ml}$. The control group was assayed without PA. The data were analysed by Lineweaver-Burk plots (Lu et al., 2006).

\subsection{Molecular modelling and computational docking study}

The molecular docking of PA to PPO and POD was analysed by AutoDock 4.2 (CCDC, UK) (MorRIs et al., 2009). The enzyme structure was produced by the Accelrys Discovery Studio 3.5 program (Accelrys Software Inc., San Diego, CA). The computational docking study was performed by minimizing the energies of PA and PPO or POD in a CHARM22 force field. Gasteiger-Hückel charges were allocated to the enzymes after water molecules were removed and all hydrogen atoms were added. During the docking process, the enzyme structures were regarded as rigid and the ligand conformers were treated as flexible. To validate the crystal structure of the ligand, the docking was carried out in 100 genetic algorithm runs, and the remaining genetic algorithm parameters were maintained at their default values. The optimal docking results were obtained when the lowest binding energy $(\Delta \mathrm{G})$ in the conformation was reached by using the following equation (FAN et al., 2013):

$$
\Delta \mathrm{G}(\mathrm{kcal} / \mathrm{mol})=\Delta \mathrm{G}(\text { intermolecular })+\Delta \mathrm{G}(\text { internal })+\Delta \mathrm{G}(\text { tor })-\Delta \mathrm{G}(\text { unbound extended })
$$

where $\Delta \mathrm{G}$ (intermolecular) is the sum of Van der Waals, hydrogen bond, electrostatic, and desolvation energies; $\Delta \mathrm{G}$ (internal) is the final total internal energy; $\Delta \mathrm{G}($ tor $)$ is torsional free energy; and $\Delta \mathrm{G}$ (unbound extended) is the unbound system's energy.

\subsection{Statistical analysis}

All experiments were carried out in triplicate. The dose-response analysis of PA on the enzymatic activity was calculated using linear regression in Microsoft Office Excel 2010. Data were analysed for statistical significance by the Proc Mixed procedure of SAS (SAS Institute, Cary, NC). 


\section{Results and discussion}

\subsection{Effect of PA on chestnut surface and interior browning}

The BDS of the control group increased to 5.8 after a six-day storage period, while those of the $0.01 \%$ and $0.05 \%(\mathrm{v} / \mathrm{v})$ PA-treated groups reached the same level, approximately 5.0 (Fig. 1A). The other groups $(0.02 \%, 0.03 \%$, and $0.04 \%$ PA) showed browning inhibition effects as the BDS decreased to negative values. Among them, the $0.04 \%$ group had the lowest BDS and was still below zero at the end of the storage time. The BDI of the control
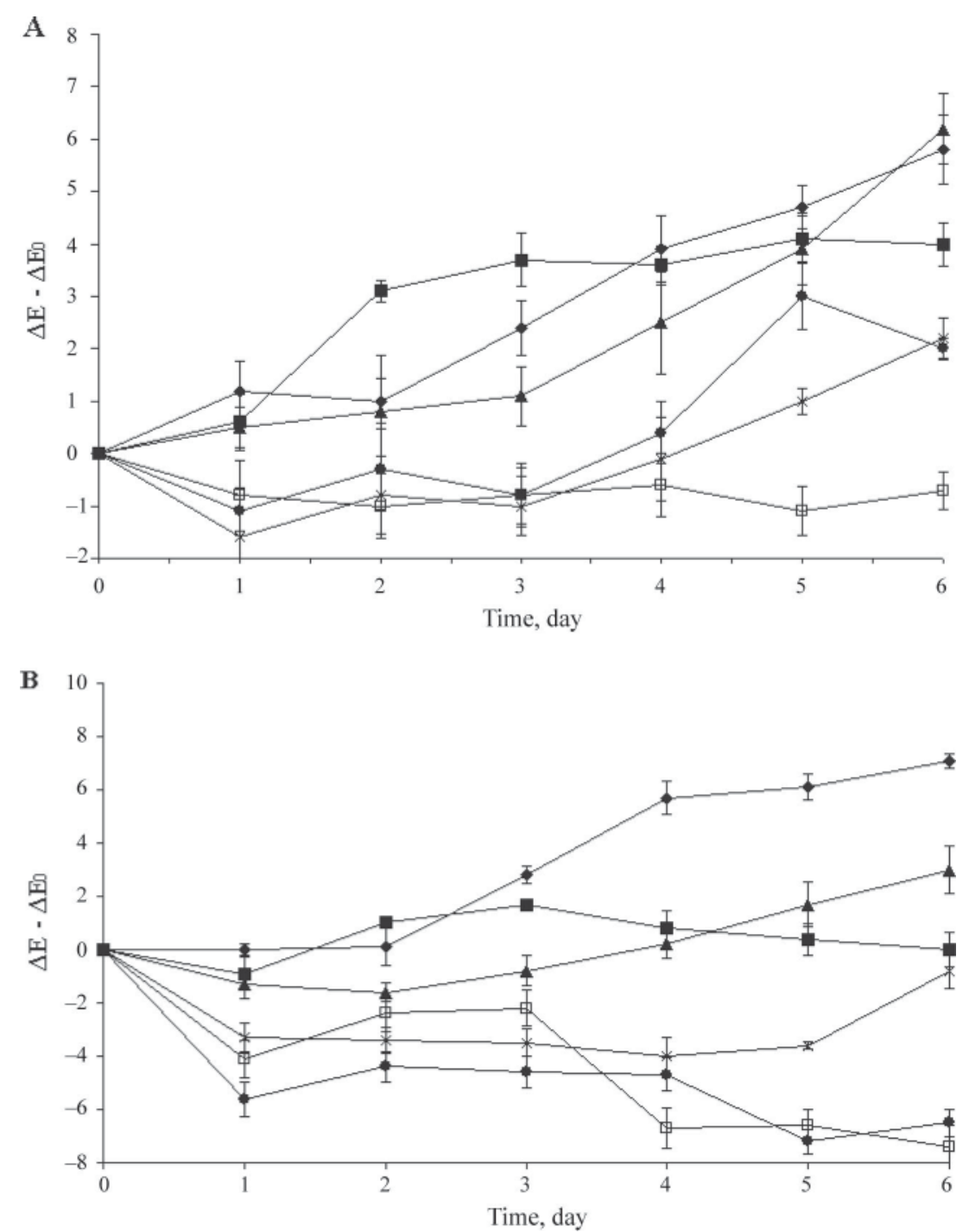

Fig. 1. Effects of different concentrations of phytic acid (PA) on the browning degree of Chinese chestnuts (A: surface; B: interior) over time. The hulled chestnuts and sliced chestnuts were immersed in PA solutions of $0-0.05 \%(\mathrm{v} / \mathrm{v})$ for $1 \mathrm{~h}$ and were stored at $4{ }^{\circ} \mathrm{C}$ for six days. Values are given as means \pm standard deviations $(n=3)$.

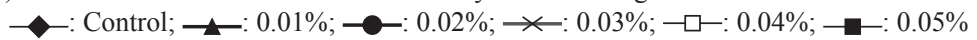


group increased to 7.1 during the 6 days, which was higher than all groups treated with PA (Fig. 1B). The BDI of the $0.01 \%$ and $0.05 \%$ PA groups ended up being positive, while the other three groups were bleached at the beginning and kept their original colour for the whole storage period. These results showed that PA could inhibit chestnut browning from outside to inside. However, the PA concentration should be carefully selected, as higher concentration $(0.05 \%)$ of PA may lead to a higher degree of browning. Du and co-workers (2012) also reported that apple juice treated with PA significantly delayed browning during processing and after 6 months of storage.

\subsection{Effect of PA on PPO and POD activities in vitro}

The specific activities of chestnut PPO and POD after the addition of different concentrations of PA are shown in Figure 2. The specific activity of PPO declined to $79.5 \%$ after the addition of $0.01 \%(\mathrm{v} / \mathrm{v})$ PA $(\mathrm{P}<0.05)$, and those of $0.02-0.05 \%$ were approximately $80-90 \%$ of the control. POD activity also declined to approximately $76 \%$ of the control $(\mathrm{P}<0.05)$ after the addition of different concentrations of PA. It can be concluded that PA can inhibit the activities of both PPO and POD. Many PPO inhibitors have been explored, and PA has been shown to restrain the PPO activity of lotus root (WANG et al., 2009) and, at $0.1 \mathrm{mM}$, inhibit the PPO activity of apple juice by $99.2 \%$ (Du et al., 2012).

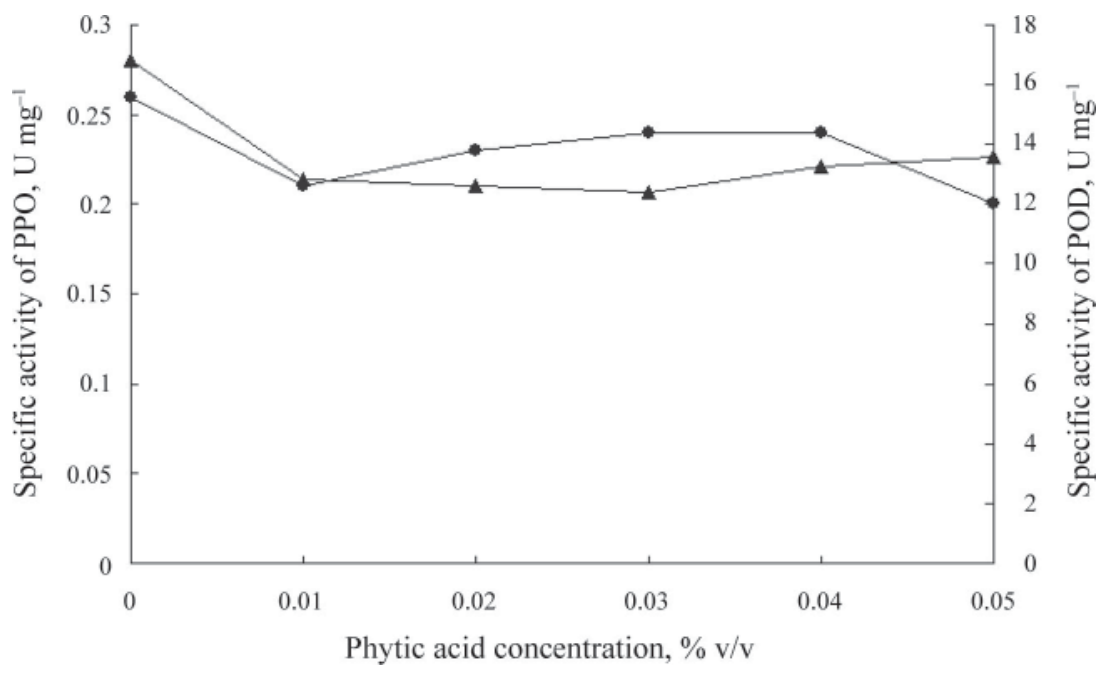

Fig. 2. Effects of different concentrations of phytic acid (PA) on the specific activities of polyphenol oxidase (PPO) and peroxidase (POD) of fresh-cut Chinese chestnuts in vitro. PPO and POD activities were assayed with different concentrations of PA $(0-0.05 \%, v / v)$. Values are given as means \pm standard deviations $(n=3)$. $\rightarrow$ - PPO; $\rightarrow$ POD

\subsection{Inhibition kinetics of PA on PPO and POD}

The inhibition kinetics of PA on PPO and POD, determined in the presence of PA, catechol, and guaiacol at $\mathrm{pH}$ 5.6, are shown in Figure 3. The X-axis intercept of a Lineweaver-Burk plot represents $1 / \mathrm{K}_{\mathrm{m}}$, while the Y-axis intercept denotes $1 / V_{\text {max }}$. The PPO and POD LineweaverBurk plots showed that the slope $\left(\mathrm{K}_{\mathrm{m}} / V_{\text {max }}\right)$ escalated with increasing concentrations of PA, 
with the values of 4.50-7.15 and 5.53-10.20 for PPO and POD, respectively (Table 1). The $V_{\max }$ remained unchanged and the $\mathrm{K}_{\mathrm{m}}$ between PPO and substrate (catechol) increased from 0.63 to $0.93 \mathrm{mM}$ when the inhibitor concentration increased from 0 to $0.05 \%$, which indicated that PA is a competitive inhibitor of PPO. The $\mathrm{K}_{\mathrm{m}}$ between POD and guaiacol increased from 18.14 to $42.22 \mathrm{mM}$ with the increased PA concentrations, however, $V_{\max }$ increased slightly from 3.28 to 4.14. The inhibition model of PA on POD exhibited analogous competitive inhibition observed from Lineweaver-Burk plots, the slight variation of $V_{\max }$ may be due to the structure transformation after PA binding on POD. PA was commonly used as a component of browning inhibitor (HICKS et al., 1996). In a previous study, PA inhibited the enzymatic superoxide source xanthine oxidase (XO) (MURAOKA \& MiURA, 2004), whose oxidation reaction mechanism is similar to those of PPO and POD. A study on free radicals and antioxidants indicated that PA was a kind of chelating agent (FANG et al., 2002).
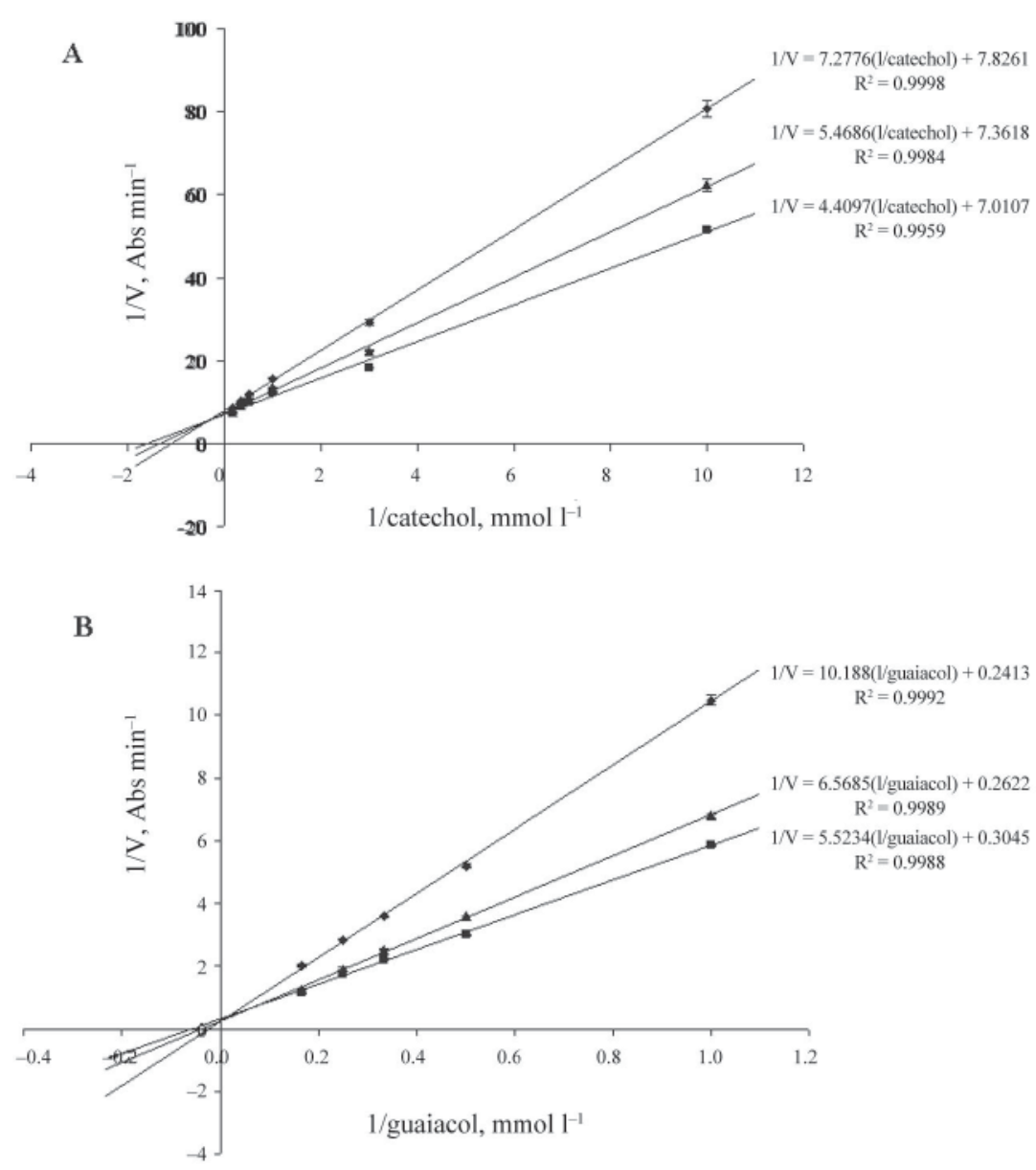

Fig. 3. Inhibition kinetics of polyphenol oxidase (PPO) (A) and peroxidase (POD) (B) by phytic acid (PA). Different concentrations of PA $(0-0.05 \%, v / v)$ were incubated in the presence of various concentrations of the substrates catechol $(0.1-6 \mathrm{mM})$ and guaiacol $(1-6 \mathrm{mM})$. Initial rates of the reactions were measured, and the results are expressed as Lineweaver-Burk plots. Values are given as means \pm standard deviations $(n=3)$.

$$
\text { A. } 0 ; \mathbf{\Lambda}: 0.02 \% ; \bullet: 0.5 \% ; \text { B. } \square ; 0 ; \mathbf{\Lambda}: 0.01 \% ; \diamond: 0.10 \%
$$


Table 1. Kinetics parameters of polyphenol oxidase (PPO) and peroxidase (POD) inhibited by phytic acid

\begin{tabular}{|c|c|c|c|c|c|}
\hline Enzyme & $\begin{array}{c}\text { Phytic acid } \\
\text { concentration } \\
(\%, \mathrm{v} / \mathrm{v})\end{array}$ & $\begin{array}{c}\mathrm{K}_{\mathrm{m}} \\
(\mathrm{mM})\end{array}$ & $\begin{array}{c}\mathrm{K}_{\mathrm{i}} \\
(\mathrm{mM})\end{array}$ & $\begin{array}{c}\mathrm{V}_{\max } \\
(\mathrm{Abs} / \mathrm{min})\end{array}$ & $\mathrm{K}_{\mathrm{m}} / \mathrm{V}_{\max }$ \\
\hline \multirow[t]{3}{*}{ PPO } & 0 & 0.63 & - & 0.14 & 4.50 \\
\hline & 0.02 & 0.74 & 1.72 & 0.13 & 5.69 \\
\hline & 0.05 & 0.93 & 1.60 & 0.13 & 7.15 \\
\hline \multirow[t]{3}{*}{ POD } & 0 & 18.14 & - & 3.28 & 5.53 \\
\hline & 0.01 & 25.05 & 0.39 & 3.81 & 6.57 \\
\hline & 0.10 & 42.22 & 0.88 & 4.14 & 10.20 \\
\hline
\end{tabular}

\subsection{Docking of PA to PPO and POD}

PPO consists of 607 amino acids with an active site located at the core of a helical bundle, in which two histidines bind two catalytic copper ions and another histidine is engaged in a thioether linkage with a cysteine residue (VIRADOR et al., 2009). POD consists of 323 amino acids and forms a grooved structure at the active site (CARLSSON et al., 2005).

The binding of PA in the PPO active site is indicated in Figure 4. PA is embedded in the active site groove of the PPO tertiary structure, and the lowest binding energy $(\Delta \mathrm{G})$ calculated by AutoDock 4.2 was $4.23 \mathrm{kcal} \mathrm{mol}^{-1}$. Of the six hydrogen bonds that are formed between PA and PPO molecules, three are formed between the PA oxygen atoms and the hydrogen atoms of GLN92, HIS236, and PHE259, while the other three hydrogen bonds are supplied by PA hydrogen atoms and the oxygen atoms of ASN240. Moreover, four $\pi-\pi$ bonds are formed between the phosphorus atoms of PA and the imidazole rings of HIS243, HIS236, and PHE259. Several reports indicated that the histidine (HIS)-bound metal active site is an important structure of the PPO active site (GARCÍA-BorRón \& SOLANo, 2002; MARuseK et al., 2006). The bonding between PA and HIS may influence the binding of substrate and PPO. Therefore, PA is a competitive inhibition agent of PPO.
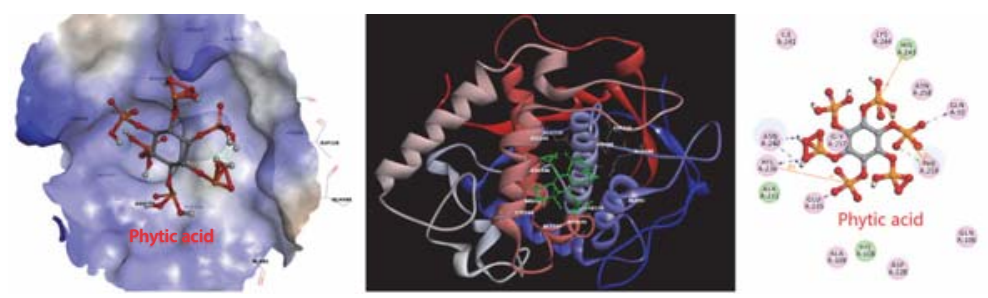

Fig. 4. Key interactions of phytic acid (PA) with the active site of polyphenol oxidase. Binding of PA in the polyphenol oxidase active site is achieved by interacting closely with key residues of the active site. Hydrogen bonds are observed between GLN92:HE22 - PA:O34, HIS236:HD1 - PA:O4, PHE259:HN - PA:O36, ASN240:OD1 - PA:H1, ASN240:OD1 - PA:H2, and ASN240:O - PA:H9. The $\pi-\pi$ bonds are observed between HIS243 - PA:P19, HIS236 - PA:P17, PHE259 - PA:P19, and PHE259 - PA:P27. 
PA fills in the groove of the active site of POD with a $\Delta \mathrm{G}$ of $6.05 \mathrm{kcal} \mathrm{mol}^{-1}$. A total of seven hydrogen bonds are formed between PA oxygen atoms and hydrogen atoms of ARG38, HIS42, and HIS170 (Fig. 5). In addition, six $\pi-\pi$ bonds are observed between the phosphorus atoms of PA and the imidazole rings of PHE221, PHE143, PHE41, and HIS170. It has been shown that peroxidative catalysis was greatly decreased by a HIS42 mutation and that PHE41 and HIS42 shield the iron-centered catalytic species (Newmyer \& De Montellano, 1995). Therefore, HIS42 and PHE41 of POD play very important roles in the catalysis. Based on the docking results, PA is an inhibitor of POD, because both hydrogen bonds and $\pi-\pi$ stacking have strong impacts on these two amino acids of POD.
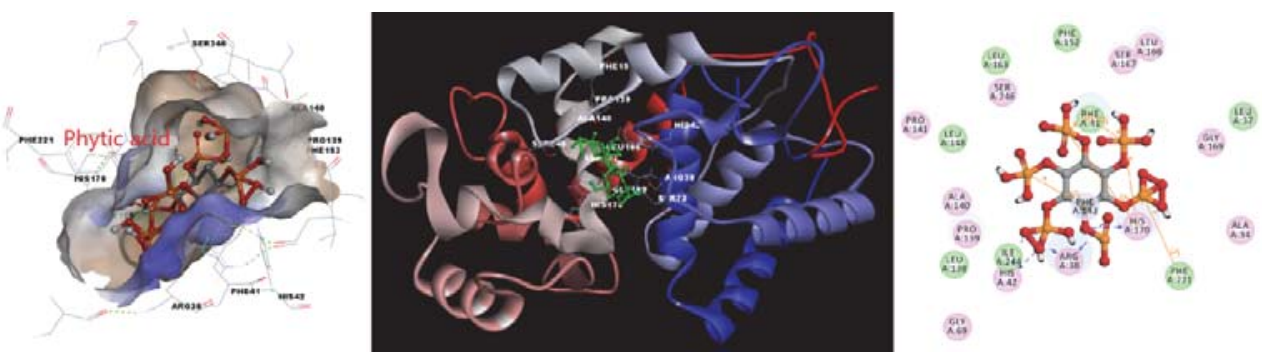

Fig. 5. Key interactions of phytic acid (PA) with the active site of peroxidase. Binding of PA in the peroxidase active site is achieved by interacting closely with key residues of the active site. Hydrogen bonds are observed between ARG38:HE - PA:O26, ARG38:HH21 - PA:O33, ARG38:HH22 - PA:O33, ARG38:HH22 - PA:O26,

HIS42:HE2 - PA:O33, HIS42:HE2 - PA:O31, and HIS170:HE2 - PA:O12. The $\pi-\pi$ bonds are observed between PHE221 - PA:P1, PHE143 - PA:P27, PHE41 - PA:P15, PHE41 - PA:P19, HIS170 - PA:P15, and HIS170 - PA:P19.

\section{Conclusions}

In this study, the inhibitory effects of PA on the browning of fresh-cut chestnuts and their associated mechanisms were determined. PA inhibited fresh-cut chestnut browning from inside to outside. PA inhibited the activities of PPO and POD, while POD was more sensitive to the inhibition effects. The inhibition kinetics and binding modes of PA with PPO and POD were determined using Lineweaver-Burk plots and AutoDock, which revealed that PA inhibited the browning of chestnuts by acting as a competitive inhibitor of both PPO and POD.

This work was supported by the financial support of "Fundamental Research Funds for the Central Universities (NO.2015ZCQ-SW-04)" from P.R. China.

\section{References}

Blaiotta, G., Di Capua, M., Coppola, R. \& Aponte, M. (2012): Production of fermented chestnut purees by lactic acid bacteria. Int. J. Food Microbiol., 158, 195-202.

Carlsson, G.H., Nicholls, P., Svistunenko, D., Berglund, G.I. \& Hajdu, J. (2005): Complexes of horseradish peroxidase with formate, acetate, and carbon monoxide. Biochemistry-US, 44, 635-642.

Chen, Z., Zhu, C., Zhang, Y., Niu, D. \& Du, J. (2010): Effects of aqueous chlorine dioxide treatment on enzymatic browning and shelf-life of fresh-cut asparagus lettuce (Lactuca sativa L.). Postharvest. Biol. Tech., 58, $232-238$. 
De la Rosa, L., Alvarez-Parrilla, E., Moyers-Montoya, E., Villegas-Ochoa, M., Ayala-Zavala, J., Hernández, J., Ruiz-Cruz, S. \& GonzÁlez-Aguilar, G.A. (2011): Mechanism for the inhibition of apple juice enzymatic browning by Palo Fierro (desert ironweed) honey extract and other natural compounds. LWT - Food Sci. Technol., 44, 269-276.

De Vasconcelos, M.C., Bennett, R.N., Rosa, E.A. \& Ferreira-Cardoso, J.V. (2010): Composition of European chestnut (Castanea sativa Mill.) and association with health effects: fresh and processed products. J. Sci. Food Agr., 90, 1578-1589.

Du, Y., Dou, S. \& Wu, S. (2012): Efficacy of phytic acid as an inhibitor of enzymatic and non-enzymatic browning in apple juice. Food Chem., 135, 580-582.

FANG, Y., YANG, S. \& Wu, G. (2002): Free radicals, antioxidants, and nutrition. Nutrition, 18, 872-879.

Fan, J., Johnson, M.H., Lila, Ma., Yousef, G. \& De Meja, E.G. (2013): Berry and citrus phenolic compounds inhibit dipeptidyl peptidase IV: Implications in diabetes management. Evid.-based Compl. Alt., doi:10.1155/2013/479505.

García-Borrón, J.C. \& Solano, F. (2002): Molecular anatomy of tyrosinase and its related proteins: beyond the histidine-bound metal catalytic center. Pigm. Cell Res., 15, 162-173.

Gounga, M., Xu, S.Y., WANG, Z. \& YANG, W.G. (2008): Effect of whey protein isolate-pullulan edible coatings on the quality and shelf life of freshly roasted and freeze-dried Chinese chestnut. J. Food Sci., 73, 155-161.

Hicks, K.B., Haines, R.M., Tong, C.B., Sapers, G.M., El-Atawy, Y., Irwin, P.L. \& Seib, P.A. (1996): Inhibition of enzymatic browning in fresh fruit and vegetable juices by soluble and insoluble forms of $\beta$-cyclodextrin alone or in combination with phosphates. J. Agr. Food Chem., 44, 2591-2594.

Lu, S., Luo, Y. \& FenG, H. (2006): Inhibition of apple polyphenol oxidase activity by sodium chlorite. J. Agr. Food Chem., 54, 3693-3696.

Marusek, C.M., Trobaugh, N.M., Flurkey, W.H. \& Inlow, J.K. (2006): Comparative analysis of polyphenol oxidase from plant and fungal species. J. Inorg. Biochem., 100, 108-123.

Morris, G.M., Huey, R., Lindstrom, W., Sanner, M.F., Belew, R.K., Goodsell, D.S. \& Olson, A.J. (2009): AutoDock4 and AutoDockTools4: Automated docking with selective receptor flexibility. J. Comput. Chem., 30, 2785-2791.

MurAoKA, S. \& MiURA, T. (2004): Inhibition of xanthine oxidase by phytic acid and its antioxidative action. Life Sci., 74, 1691-1700.

Newmyer, S.L. \& De Montellano, P.R.O. (1995): Horseradish peroxidase His42-Ala, His42-Val, and Phe41-Ala mutants - Histidine catalysis and control of substrate access to the heme iron. J. Biol. Chem., 270, 1943019438.

Virador, V.M., Reyes Grajeda, J.P., Blanco-Labra, A., Mendiola-Olaya, E., Smith, G.M., Moreno, A. \& Whitaker, J.R. (2009): Cloning, sequencing, purification, and crystal structure of Grenache (Vitis vinifera) polyphenol oxidase. J. Agr. Food Chem., 58, 1189-1201.

WANG, X., JiAnG, L. \& WANG, Z. (2009): Enzymatic browning of lotus roots and its control during storage. T. Chin. Soc. Agr. Eng., 25, 276-280.

Zhou, D., Li, L., Wu, Y., Fan, J. \& OuYang, J. (2015): Salicylic acid inhibits enzymatic browning of fresh-cut Chinese chestnut (Castanea mollissima) by competitively inhibiting polyphenol oxidase. Food Chem., 171, $19-25$. 